\title{
Plans for the future and the ability to predict as cognitive navigators of a person's social success
}

\author{
Julia E. Makarevskaya ${ }^{1, *}$ and Zinaida I. Ryabikina ${ }^{2}$ \\ ${ }^{1}$ Sochi State University, Plastunskaya str. 94, 354003, Sochi, Russia \\ ${ }^{2}$ Kuban State University, Stavropolskaya str. 149, 350000, Krasnodar, Russia
}

\begin{abstract}
Social success is an ambiguous category that has both external and internal criteria. Despite the difficult comprehension of the criteria and the ambiguity of their interpretation in different cultures and social strata, the desire for success in the form of various behavioral tendencies and manifestations is considered inherent in most people. The research results presented in the article were obtained on samples of different age groups: adolescence, young, adult age periods (from 17 to 45 years). The criteria of social success are considered through the prism of the leading activity of the age and are used as the basis for differentiating the samples into socially successful and unsuccessful respondents. The study is comparative in nature and shows that the cognitive markers of socially successful respondents differ from the mental trajectories of socially unsuccessful respondents. In adolescence, social success is accompanied by clear formulated goals and conscious plans for the future; in young and adult ages, while maintaining awareness of plans, socially successful respondents also have a high level of predictive abilities, expressed in the validity of the thinking process, flexibility of thinking, plasticity of ideas and the prospect of causal relationships. These cognitive characteristics allow a person to build mental processes in such a way that they accompany the person's social success.
\end{abstract}

\section{Introduction}

The category of success is discussed in various scientific fields, such as philosophy, sociology, political science, economics, in various management theories.

In the West, there are whole schools of development of success and success is cultivated as a certain style of behavior and life [1, 2, 3, 4, 5, 6, etc.], in Russia the attitude to this topic is more complicated and ambiguous.

Currently, the features of the social situation of personality development (including economic, social, political, and cultural processes) form an example of a successful person (in personal, professional, social terms) in the public consciousness as an idea, and success, life achievements are one of the basic values of the modern Russian at the present time $[7,8,9,10,11,12,13$, etc. $]$.

\footnotetext{
* Corresponding author: sochi@mail.ru
} 
Studies by K. Levin and his followers in this area show that experiences of success and failure arise only within the zone of the subject's capabilities and in activities that are personally significant for the individual and, in addition, achievement in activity is assessed as success only if it is attributed to the individual's own efforts (K. Levin).

Despite the importance of the value of success both for a particular individual and for society, in Russian psychology, until recently, only some of the applied aspects of this problem were considered - mainly in the context of pedagogical activity (in matters of academic performance and success in learning), engineering psychology (in the area of achievement of labor productivity) $[14,15]$. Recently, the terms "achievement" and "success" have begun to attract the attention of researchers in the field of the psychology of professional activity $[16,17]$.

Society estimates the success or failure of an individual based on the presence or absence of an objective result (goal achievement) and the significance of the activities performed in accordance with the current system of social values.

The subjective assessment of the result of the performed activity is emotionally experienced by the person as success (pleasure, joy, etc.) or failure (disappointment, resentment, anger, etc.), in contrast to the "result", the receipt of which may not cause emotional feelings if the activity turns out to be of little importance for the individual.

However, in any case, in order to be understand oneself as having achieved success, a person should at least promptly carry out certain types of activities, no worse and more original than others performing the same activities in a similar age period (that is, on time).

Thus, a personal problem in the timely achievement of social success is fixed, under visible similar objective conditions and, as a consequence, the possibility of dividing people into successful and unsuccessful in social terms.

In addition, we see a question about the difference in the criteria of social success for people of different age groups as an interesting. That is why in this study, questions about cognitive navigators of a person's social success were posed and solved by different methods. At the same time, by navigators, we mean certain mental paths (roads), directions of thoughts that accompany the social achievements of an individual.

Out of here, we formulate the assumption that the social success of an individual is accompanied by specific cognitive trajectories and abilities (opportunities).

\section{Materials and methods}

Based on the content of the concept of social success, it can be assumed that the methods of its fixation may be objective criteria for the achievement of an individual in certain types of activity. At the same time, the activity should be personally significant for the subject and be essential for the formation of the social future of the individual.

This type of activity in psychology is the leading activity, the purpose of which is to ensure the completeness of mental development and the effectiveness of the social functioning of the individual.

It was according to this parameter that the types of activity of the subjects, included in the sample, were selected.

It is known that the leading types of activity in different age periods differ.

Therefore, for the subjects of adolescence, the criteria of their success in educational and professional activity were assessed, and for the subjects of adult and mature ages the criteria of their success only in professional activity were evaluated.

Thus, one of the research methods was the analysis of the selection of objective criteria for the success of the training-professional and professional activities of the respondents.

Based on these criteria, samples were formed: 
- young people and girls aged 17-21. $\mathrm{N}=100$ people, average age -20.21 years, $19 \%$ men and $81 \%$ women.

- heads of various management levels. $\mathrm{N}=30$ people. First-line management (10 people), middle management (10 people) and top management (10 people). The average age in the sample in general is 31.60 , in the sample of first-line management -22.5 , middle management -31.3 , top management -41 .

Both samples underwent additional differentiation according to the level of success in the leading type of activity of the corresponding age periods.

In the sample of adolescents, the average academic performance score $(M x=4.29)$ and standard deviation $(\sigma=0.61)$ for this sample were calculated.

According to the bell curve, respondents with values in the range of $M x \pm \sigma$, that is, from 3.68 to 4.9 points, were charged to the average level of social success. High values (level 3) in this sample were considered indicators of academic performance from 4.9 points - up to 5 points exactly, and respondents with values ranging from 3.68 to 2.87 points - were included in the sample of socially unsuccessful ones.

In numerical terms, the differentiation of the sample by the levels of academic performance is as follows: low-performing people - 22 people $(22 \%)$, average-performing people - 59 people (59\%), high-performing people - 19 people (19\%).

The sample of mature age was differentiated into levels of social success according to the criteria of the management level (position held): grass-roots, middle, highest.

That is, in a comparative study, 6 groups of respondents were identified: 3 of which are in the range of the adolescent age period, 3 - in the range of adult age.

Diagnostic techniques:

- for a sample of adolescents: test "Life-meaning orientations" D.A. Leontiev (adapted version of the Purpose-in-Life Test (PIL) by James Crumbaugh and Leonard Maholic) [18];

- for managers: the "Predictive task" test [19].

The results of the LMO test reflect the general meaningfulness of life and the orientation of the individual towards conscious goal-setting, achievement of the result, concentration on the life process and / or on oneself.

An indicator of the ability to predict are the levels of success in establishing causal relationships, planning, transforming ideas, proposing and developing hypotheses by a person $[18,19,20,21]$.

The results of the "Predictive task" test can be assessed by 19 parameters [19].

\section{Results}

The use of the "LMO" methodology made it possible to diagnose the general indicator of the meaningfulness of the subjects' life $(M x=106.91)$, goals in life $(M x=33.1)$, life saturation $(M x=32.51)$, satisfaction with self-realization $(M x=27.15)$, locus of I-control $(M x=21.66)$ and locus of life-control $(M x=32.41)$. The medians of the statistical sets of values according to the methodology scales do not significantly differ from the average, therefore, the statistical series are free from outliers. The data obtained correspond to the standards suggested by the author of the methodology for evaluating the results.

Subsequent processing of the results consisted of comparing the average values in the samples of low and highly successful subjects ( 1 and 3, respectively).

Student's t criterion showed that:

$\checkmark \quad$ the severity of signs "meaningfulness of life" $(p=0.007)$ and "purpose of life" ( $p=$ $0.006)$ in samples 1 and 3 differs at a high level of statistical significance $(p \leq 0.01)$;

the severity of signs "emotional saturation of life - process" $(p=0.038)$, "satisfaction with self-realization - result" ( $p=0.019)$, "locus of I-control" ( $p=0.018)$, "locus of lifecontrol" $(p=0.02)$ in samples 1 and 3 is significantly different $(p \leq 0.05)$. 
$\checkmark \quad$ The meaningfulness of the present, past and future by a person being for a long period in conditions of social success is higher than that of a low-successful person, which can probably be expressed in the personality's determination, if not only of the meaning of life in general, but also of some of its aspects (for example, prospects for the future $(p=$ $0.006)$, the fullness of the current moment of life $(p=0.038)$, or comprehension of the past $(p=0.019)$; as well as ideas about the strength of one's personality $(p=0.018)$ and the ability to control one's life $(\mathrm{p}=0.02)$.

The recorded differences suggest the existence of a concatenation between social success and various aspects of the meaningfulness of the subjects' lives. To test this hypothesis, the calculation of the Pearson correlation coefficient was applied.

The results of the correlation analysis recorded the concatenation between the success of the subjects in the leading activity and the general indicator of the meaningfulness of their life $(p=0.026)$, the awareness of life goals $(p=0.009)$, the fullness of the meaning of the current activity $(p=0.011)$, satisfaction with the achieved results $(p=0.02)$, as well as ideas about the strength of their I $(p=0.01)$ and the conviction in control over their own life $(p=$ $0.02)$.

The direct ratio of meanings and the closeness of the identified concatenation suggests that the higher the success of the individual in the leading and significant for him/her activity, the more he/she is inherent in comprehension of his/her own life, in awareness of the focus and time perspectives of the personal I, interest in current real life events, satisfaction with his/her past, consciousness of himself/herself as a strong personality with sufficient capabilities to build and control his/her life in accordance with his/her goals.

To determine the direction of the concatenation of influence between success and the components of the meaningfulness of a person's life, one-way analysis of variance (ANOVA) was used.

From the results of the analysis, it can be concluded that the level of a person's achievements in activities that are significant for his/her future affects the meaningfulness of life in general $(p=0.054)$, the level of goal-setting of the individual $(p=0.029)$, the level of development of the personality's worldview beliefs in the ability to control one's own life ( $p$ $=0.029)$ and ideas about the capability to exercise this control $(p=0.047)$.

In general, the adolescent personality under conditions of social success can more express:

$\checkmark \quad$ meaningfulness of life in general $\left(\mathrm{r}=0.223^{*}\right)$;

$\checkmark$ awareness of the time perspective and direction of one's own life ( $\left.\mathrm{r}=0.260^{* *}\right)$;

$(* *$ - the correlation is significant at the 0.01 level, *- the correlation is significant at the 0.05 level)

The social success of an individual in the leading activity that is significant for his/her future efforts acts as a factor that determines the meaningfulness of life as a whole $(p=0.054)$, the level of goal-setting of the individual $(\mathrm{p}=0.029)$, the level of development of the personality's worldview beliefs in the ability to control his own life $(p=0.029)$ and ideas about the capability to exercise this control $(\mathrm{p}=0.047)$.

However, the tasks of social achievement are not limited by the adolescence, but rather become even more relevant, therefore stage $2-1$ of the study was devoted to testing the hypothesis on a sample of young and adult ages.

Table 1. Empirical indicators of the test "predictive task" average values for 3 groups.

\begin{tabular}{|c|c|c|c|}
\hline & Low level & Middle level & High level \\
\hline Average score & 25.9 & 31.3 & 37.8 \\
\hline
\end{tabular}

From the data presented in the table, it can be seen that the average values of the severity of the ability to predict differ in the samples of the low, middle and high management levels. 
Pair-wise comparison of the means in 3 groups of subjects was carried out using the Student's t-test.

Table 2. Empirical values of the Student's t-test and the level of significance of the revealed differences in the groups of subjects.

\begin{tabular}{|l|c|c|}
\hline \multicolumn{1}{|c|}{ Predictive ability } & Student's empirical t-test & Sig. (2-tailed) \\
\hline Low-middle level & -3.918 & 0.001 \\
\hline Low-high level & -12.742 & $0.000 \ldots$ \\
\hline Middle-high level & -4.364 & 0.001 \\
\hline
\end{tabular}

As can be seen from the obtained values, the greatest differences in the ability to predict were found between the leaders of the low and top management $(p \leq 0,000 \ldots)$.

Table 3. Quantitative indicators of 19 parameters of predictive ability.

\begin{tabular}{|c|c|c|c|}
\hline $\begin{array}{c}\text { Tasks and parameters of predictive } \\
\text { ability }\end{array}$ & $\begin{array}{l}\text { Management } \\
\text { levels }\end{array}$ & & \\
\hline & $\begin{array}{c}\text { Low level (total } \\
\text { points) }\end{array}$ & $\begin{array}{l}\text { Middle level } \\
\text { (total points) }\end{array}$ & $\begin{array}{c}\text { High level } \\
\text { (total points) }\end{array}$ \\
\hline \multicolumn{4}{|l|}{ Task 1} \\
\hline $\begin{array}{l}\text { 1. The level of verbal generalization of } \\
\text { consequences. }\end{array}$ & 20 & 40 & 55 \\
\hline $\begin{array}{l}\text { 2. The validity of the highlighted } \\
\text { consequences. }\end{array}$ & 20 & 25 & 50 \\
\hline 3. Perspective of the consequences. & 21 & 27 & 55 \\
\hline $\begin{array}{l}\text { 4. The logic of constructing } \\
\text { consequences. }\end{array}$ & 10 & 25 & 40 \\
\hline \multicolumn{4}{|l|}{ Task 2} \\
\hline $\begin{array}{l}\text { 7. The level of verbal generalization of } \\
\text { reasons. }\end{array}$ & 23 & 60 & 60 \\
\hline $\begin{array}{l}\text { 8. Completeness of cause-and-effect } \\
\text { relations. }\end{array}$ & 25 & 60 & 60 \\
\hline $\begin{array}{l}\text { 9. The relevance of cause-and-effect } \\
\text { relations. }\end{array}$ & 22 & 50 & 54 \\
\hline \multicolumn{4}{|l|}{ Task 3} \\
\hline 10. Awareness of the purpose of the plan. & 29 & 50 & 59 \\
\hline 11. Completeness of planning operations. & 20 & 45 & 45 \\
\hline $\begin{array}{l}\text { 12. The prospect of cause-and-effect } \\
\text { relations. }\end{array}$ & 10 & 32 & 40 \\
\hline \multicolumn{4}{|l|}{ Task 4} \\
\hline 13. The latitude of the association area. & 50 & 53 & 55 \\
\hline 14. The variability of the association area. & 22 & 45 & 49 \\
\hline 15. Plasticity of representations. & 15 & 23 & 38 \\
\hline \multicolumn{4}{|l|}{ Task 5} \\
\hline $\begin{array}{l}\text { 16. The breadth of the search for } \\
\text { hypothesizing. }\end{array}$ & 21 & 33 & 40 \\
\hline $\begin{array}{l}\text { 17. Accounting the requirements of the } \\
\text { conditions when hypothesizing. }\end{array}$ & 53 & 54 & 56 \\
\hline 18. Flexibility of hypotheses. & 13 & 24 & 60 \\
\hline 19. Validity of hypotheses. & 12 & 25 & 44 \\
\hline
\end{tabular}

After the primary processing of the empirical data, it can be seen that the average values for all 19 parameters of the predictive ability of the subjects increase in the direction from the low to the middle. 
The measures of the central trend show that the spread of values from the low level to the high level decreases, which indicates a greater stability of the empirical values in the sample of the top management level.

Table 4. Measures of the central trend in 3 groups.

\begin{tabular}{|l|c|c|c|}
\hline & Low level & Middle level & High level \\
\hline Average score & 21.4 & 38.2 & 49.5 \\
\hline Minimum & 10 & 23 & 36 \\
\hline Maximum & 53 & 60 & 60 \\
\hline $\boldsymbol{\sigma}$ & 12.056 & 13.294 & 8.269 \\
\hline
\end{tabular}

Pair-wise comparison of differences (Student's t-test) revealed significant differences between all levels of management in all parameters of the "Predictive task" test. By clarifications, it can be considered that the differences in the level of predictive ability are somewhat greater between the middle and high level management (temp. $=-4.364$ ) than between the low and middle level management (temp. $=-3.918$ ).

In general, according to this method, it was determined that the level of development of the ability to predict is expressed:

- at the low level: low in $30 \%$ of the subjects, medium $-20 \%$, high $-50 \%$;

- in the middle level: low in $10 \%$ of the subjects, high $-30 \%$, very high $-60 \%$;

- at the high level - very high - $100 \%$.

The data obtained indicate that the representation of a very high level of predictive ability among top managers is expressed by $100 \%$.

\section{Discussion}

The results of the study, obtained on a sample of adolescents, were repeatedly checked by us and found confirmation.

Due to the fact that the criteria of social success are still controversial, it can be said that in some cases respondents who were unsuccessful in their leading activities could successfully fulfil themselves in other spheres of their lives and thereby neutralize the lack of achievements in activities that are significant for a given age.

That is, in interpreting the results obtained, we cannot unequivocally say that planning for the future builds social success, but we can assert that clear plans for the future accompany the recognized social achievements of young men and women in the leading activity for their age - educational and professional.

So, more socially successful young men and women statistically significantly differ from unsuccessful ones in that they have clear plans for the future in the structure of their lifemeaning orientations.

Their plans are formulated as goals for the future, "which give life meaning, direction and time perspective."

General personality characteristics: purposefulness.

An additional survey of respondents $(\mathrm{N}=178)$ made it possible to describe the pithy characteristics of this cognitive (mental, attributive) parallel of social success in adolescence: "I strive to achieve my goal", "I strive for knowledge", "I have a desire to learn", "I am purposeful", "I want to achieve success", "there are goals in life", "there is a goal for which I study".

That is, we want to emphasize once again that in adolescence, the achievements recognized by society in activities that are significant for the future of individual are perceived as social success and are accompanied by clearly understood plans for the future.

Do these results guarantee continued social success when leading activities change? This is the main question for the second stage of our study. 
It is the samples of young and mature age, differentiated by the level of career achievements, that allow us to move further in the study of the cognitive components of a person's social success.

The results obtained on a sample of managers of different levels show how significant predictive ability is in a successful managerial career.

In this case, we cannot say that it is predictive ability that underlies the successful career of managers. Perhaps the performance of managerial functions stimulates the development of predictive mindset. However, the severity of these abilities in our study increases statistically significant with an improvement in the social status of respondents from the low to the high management level.

At the same time, it is interesting that the differences in the predictive ability of respondents between the low and middle management levels are statistically less expressed than between the middle and high management levels. That is, it is easier to cognitively rebuild and take a career step from the low management level to the middle one than from the middle to the high one.

Based on the results of a quantitative analysis of empirical data, it can be concluded that the predictive ability of top managers is much more developed in all structural parameters. This means that high level managers have more developed logical, predictive functions of thinking, as well as mental operations of generalization, analysis of information, and such qualities of the mind as plasticity, flexibility, breadth of thinking, the possibility of distraction and abstraction.

So, the quantitative and qualitative analysis of empirical data made it possible to conclude that predicting is most clearly manifested among top managers in comparison with the middle and low managers.

Thus, we understand that career aspirations are not the only criteria for social success, however, as a sign of material well-being and employment, the level of the position held is a category in cognitive schemes that describes social well-being.

\section{Conclusion}

On the basis of the research carried out, it can be concluded that social success, recognition of the achievements of an individual in activities that are significant for him/her cause clarity in the consciousness of the time perspective, an increase in the feeling of the strength of oneself and faith in one's own ability to manage his/her own life.

If in adolescence it is quite enough to decide on plans for the future, to have clear cognitive ideas about life goals, then in young and mature ages high social success (career achievements) is most accompanied by such mental abilities of the individual as the validity and prospectivity of predicting various consequences, prospectivity of cause-and-effect relations of events and circumstances, plasticity of ideas, flexibility and validity of hypotheses.

That is, we see that awareness of thoughts from adolescence does not leave a socially successful person, and predictive thinking abilities are acquired (or developed), which allow the person to literally see the future.

We see prospects for research in the study of the emotional and volitional components of the individual, accompanying the achievement of social success.

\section{References}

1. W. James, Great Men and Their Environment (Kessinger Publishing LLC, Whitefish, 2005) 
2. R.M. Ryan, E.L. Deci, The American psychologist 55, 68-78 (2000) https://doi.org/10.1037/0003-066X.55.1.68

3. K. Lewin, Field theory in Social Science (Sensor, St. Petersburg, 2000)

4. M. Thomas, A New Attitude: Achieving Personal and Professional Success by Keeping a Positive Mental Outlook (AST Publishing Group, Moscow, 2006)

5. S. Covey, The Seven Habits of Highly Effective People: Restoring the Character Ethic (Alpina Publisher, Moscow, 2017)

6. N. Hill, Think and Grow Rich! (Popuri, Minsk, 2006)

7. M.S. Guseltseva, A.G. Asmolov, Volga pedagogical search 2(32), 14-23 (2020) https://doi.org/10.33065/2307-1052-2020-2-32-14-23

8. G.U. Soldatova, S.V. Chigarkova, European Proceedings of Social and Behavioural Sciences, Future Academy 49, 636-643 (2018). https://dx.doi.org/10.15405/epsbs.2018.11.02.73

9. Z.I. Ryabikina, I.G. Makarevskaya, Yu.E. Makarevskaya, EpSBS 49-ICPE 42, 392-401 (2018) doi: 10.15405/epsbs.2018.11.02.42

10. D.A. Leontiev, Economic and Social Changes Journal (Public Opinion Monitoring) 1 (2020) https://doi.org/10.14515/monitoring.2020.1.02

11. M. Melia, Success is a personal matter: How not to lose yourself in the modern world (Prosveshenie publishing house, Moscow, 2012)

12. O. Makhmudov, Molodoy Uchenyy 14.1(148.1), 19-21 (2017) https://moluch.ru/archive/148/42020/

13. K.G. Klein, D.A. Leontiev, V.Yu. Kostenko et al., Psychological Science and Education 24(5), 47-57 (2019) https://doi.org/10.17759/pse.2019240505

14. D.A. Leontiev, K.G. Klein, Moscow University Bulletin. Series 14: Psychology 4, 106119 (2018) https://doi.org/10.11621/vsp.2018.04.106

15. D.A. Leontiev, E.N. Osin, S.Sh. Dosumova et al., Psychological Science and Education 23(6), 55-66 (2018) https://doi.org/10.17759/pse.2018230605

16. A.S. Kuznetsova, M.A. Titova, T.A. Zlokazova, Journal Moscow University Bulletin. Episode 14: Psychology 1, 51-68 (2019) https://doi.org/10.11621/vsp.2019.01.51

17. A. Smirnova, Materials of the All-Russian scientific and practical conference dedicated to the 100th anniversary of the Federal State-Funded Educational Institution of Higher Education "Financial University under the Government of the Russian Federation" (Publishing House - $\quad$ South, Krasnodar, 2018) https://www.elibrary.ru/item.asp?id=35373543\&selid=35373569

18. D. Leontiev, Life-Meaning Orientation Test (LMO). Psychodiagnostic series (Publishing house "Smysl", 2004)

19. L. Regush, Psychology of predicting: advances in understanding the future (Publishing house "Rech", St. Petersburg, 2003)

20. D.A. Leontiev, Siberian Psychological Journal 62 (2016) https://doi.org/10.17223/17267080/62/3

21. V.I. Pishchik, Humanities \& Social Sciences Reviews 8(4), 917-930 (2020) https://doi.org/10.18510/hssr.2020.8489 